\title{
Violência em acontecimentos políticos: jornalismo e lawfare no caso Lula
}

\author{
Carlos Alberto Carvalho' \\ http://orcid.org/0000-0001-8433-8794 \\ Maria Gislene Carvalho Fonseca' \\ https://orcid.org/0000-0003-3201-1946 \\ I - UFMG \\ Belo Horizonte (MG), Brasil
}

Resumo: Este texto examina as ações que levaram à condenação, à prisão e ao impedimento da candidatura à presidência em 2018 do ex-presidente Luiz Inácio Lula da Silva, tomando como referência o conceito de acontecimento entendido como violência, bem como as dimensões de violência na política. Os acontecimentos envolvendo Lula são identificados como práticas de lawfare, guerra jurídica com participação da mídia, que visa minar pessoas ou instituições. Teoricamente, trabalhamos com o conceito de acontecimento e com as relações entre política e violência. Como metodologia, além de revisão conceitual, recorremos a um conjunto de notícias que abordaram os acontecimentos envolvendo Lula.

Palavras-chave: acontecimento; violência: jornalismo; política; Lula.

Abstract: Violence in political events: journalism and lawfare in the Lula case - This paper examines the actions that led to the condemnation, arrest and impediment of the candidacy for the presidency in 2018 of the former president Luiz Inácio Lula da Silva, taking as reference the concept of event understood as violence, as well as the dimensions of violence in politics. The events surrounding Lula have been identified as practices of lawfare, legal warfare with media participation that aims to undermine people or institutions. Theoretically, we take notions of events and the relations between politics and violence. As a methodology, in addition to conceptual review, we used a set of news that addressed the events involving Lula.

Keywords: event; violence; journalism; politics; Lula.

\section{Introdução}

Historicamente, o conceito de acontecimento resvala, em diversas abordagens teóricas, nas dimensões de violência que Ihe seriam próprias, a exemplo de uma 
enchente devastadora ou de assassinatos em massa. No entanto, não necessariamente são aprofundadas as dimensões das violências, tanto físicas - as perdas materiais e as vidas ceifadas -, quanto simbólicas - as inseguranças psicossociais diante de ameaças da natureza ou da ação de milícias ou de agentes governamentais componentes dos exemplos citados. Metáforas como eclosão, irrupção ou ruptura, usadas em noções de acontecimento, atestam suas íntimas relações com a violência.

Acontecimentos políticos como o holocausto ou o apartheid são facilmente identificados como violentos. Entendemos os acontecimentos políticos, a partir de casos como o apartheid, não somente como ocorrências pontuais, mas como realidades que, em sua longa duração, promovem outros acontecimentos, a exemplo de prisões políticas e assassinatos, como estratégias para a sua manutenção. Menos óbvias, no entanto, podem ser as correlações entre alguns acontecimentos políticos - que nos interessam neste artigo em relação aos eventos envolvendo o ex-presidente Lula - e a violência, posto que apresentados como processos em tese respaldados por fundamentos jurídicos, bases éticas e parte da própria dinâmica das disputas políticas e das correções necessárias, por exemplo, para o combate à corrupção.

Se as relações entre acontecimento, política e violência são por si complexas, o nível de dificuldade aumenta quando à equação acrescentamos o jornalismo. Toma-se como pressuposto, por exemplo em autores como Pierre Nora (1984, 1993), que a mídia depende de acontecimentos e acontecimentos precisam da mídia para reverberarem.

A condenação, a prisão e o impedimento da candidatura do ex-presidente Lula às eleições para a presidência em 2018 foram acontecimentos que tiveram as mídias tradicionais como aliadas aos posicionamentos de alguns agentes da Polícia Federal e do Poder Judiciário (Ministério Público, tribunais e juízes). É a construção destes acontecimentos, com suas dimensões de violência, que nos interessa investigar. São acontecimentos denunciados por juristas de diversos matizes como tendo motivações mais políticas do que jurídicas (PRONER, et al, 2017; 2018), interferindo no processo eleitoral de 2018, que teve Lula em primeiro lugar em todas as pesquisas de intenção de votos mesmo após seu encarceramento, que aliás, aumentou as intenções de nele votar (GIELOW, 2018).

\section{Metodologia}

Nossa pesquisa se ampara em um corpus de mais de duas dezenas de notícias publicadas por mídias online tradicionais (Uol, G1, Exame, Folha de S.Paulo) e por aquelas que se apresentam como alternativas (DCM, Jornal GGN, Brasil 247). O objetivo é refletir sobre os acontecimentos ligados à violência, não somente na sua eclosão, mas também nas tentativas de controle dos transbordamentos deles derivados. Nesse sentido, ganha relevância o que a defesa de Lula e juristas qualificam como prática de lawfare, o que inclui alianças 
entre setores da mídia, do Judiciário, do Ministério Público e da Polícia Federal na forja de elementos para condenar o líder político sem as devidas provas irrefutáveis de culpa, revelando práticas persecutórias e de destruição de reputação (PRONER et al, 2017; 2018).

A escolha do corpus de narrativas que elegemos guiou-se pela recolha de textos que começa pela condução coercitiva do ex-presidente Lula e termina na decisão de impedi-lo de candidatar-se à Presidência nas eleições de 2018, incluindo as proibições de que ele dê entrevistas. Consideramos três orientações metodológicas.

A primeira foi guiada pela possibilidade de explicitar as dinâmicas de violência dos acontecimentos e da política como violência que se revelam nas narrativas escolhidas. A segunda diz da necessidade de selecionar narrativas que fossem, elas próprias, parte da informação sobre os acontecimentos como condição necessária à nossa compreensão do fenômeno sob investigação. O último critério foi selecionar narrativas tanto das mídias tradicionais, como daquelas que se apresentam como alternativas a elas, em muitos casos reivindicando posições editoriais de esquerda ou de centro-esquerda. As abordagens distintas entre as duas modalidades de mídias são indicativas das próprias dinâmicas de apreensão dos acontecimentos, dos modos como as construções narrativas reivindicam interpretações distintas, disputas de sentido e jogos de poder.

Na esteira das proposiçõos de Pierre Nora (1984; 1993) sobre as dificuldades de compreensão de acontecimentos em curso que têm as mídias como parte das suas dinâmicas, enfrentamos o desafio de analisar o acontecimento do e no presente, e não como algo pertencente ao passado. Inscrito no mesmo tempo cronológico de quem escreve este artigo, as inquietações políticas com os eventos envolvendo Lula constituem parte indissociável das análises aqui empreendidas, que se valeram das discussões da Rede Historicidades, particularmente sob o tema Movimentos epistêmicos, políticos, estéticos e culturais do tempo. Se compreender acontecimentos passados implica em recorrer a arquivos, testemunhos, rastros e outras possibilidades de reconstituição do que ocorreu sem a presença de quem pesquisa, não menos complexa é a atividade de ser ao mesmo tempo testemunha e agente que sofre e age sobre um acontecimento em curso.

\section{Acontecimento}

Para Quéré (2006), o acontecimento é um fenômeno que rompe a normalidade do tempo e do curso da ação. Ele apresenta um caráter hermenêutico, podendo afetar de forma diferente cada indivíduo, no mínimo pela necessidade de interpretá-lo. Deste modo, o lugar do acontecimento se dá na organização da ação e na estruturação da experiência a partir de interações, organizações e agenciamentos.

Ainda para Quéré (2012), o acontecimento possui dupla vida, como acontecimento existencial e acontecimento-objeto: 
Os acontecimentos deixam de ser, assim, simples mudanças existenciais. Eles se transformam em objetos dos quais nos tornamos conscientes, em "coisas com significados", porque são estes - e, em particular, a causalidade, a individualidade e as potencialidades do acontecimento - que suscitam, na prática, nosso interesse. O acontecimento ganha, por conseguinte, novos modos de operação e novas características. Ele se torna não só um objeto e uma fonte de inferências e de raciocínios, mas também um meio de ação controlada. Com efeito, servimo-nos desse tipo de objeto cognitivo-discursivo para intervir no curso dos acontecimentos, a fim de canalizá-lo ou atenuar sua brutalidade. Os acontecimentos-objetos tornam-se, assim, agentes da história que se faz (QUÉRÉ, 2012, p. 31).

A ideia de brutalidade interessa-nos particularmente, pois é um dos indícios de que os acontecimentos existem e acionam a dialética agir-sofrer principalmente pelos elementos de violência que nos fazem participar das muitas maneiras de torná-los, para nós, acontecimentos-objetos. Lidar com o acontecimento, se para algumas pessoas e instituições implica em atenuar a brutalidade, ou em lutar contra ela, para outras revela a promoção da brutalidade.

Os acontecimentos-objetos nos acionam individualmente, mas também, como propõe Pierre Nora (1983, p. 47), modernamente "não há acontecimento sem mídia". Neste processo, esta é ao mesmo tempo palco e atriz, atuando com ou contra outros atores e atrizes sociais nas disputas de sentido e nos jogos de poder em torno dos significados e desdobramentos dos acontecimentos. Palco porque é um espaço onde se dá visibilidade às narrativas sobre os acontecimentos, e atriz porque não é externa a eles e às suas repercussões, mas os compõe como uma das partes interessadas. Propomos pensar as mídias como parte constitutiva dos atores e atrizes sociais responsáveis pelas marcas de violência que caracterizam os acontecimentos envolvendo o ex-presidente Lula. Nessa perspectiva, se há uma dupla vida do acontecimento - em suas dimensões existenciais e de objetos - pensamos que ambas podem resultar historicamente de ações concretas de agentes que, ao desencadearem um acontecimento que em si já possui as potencialidades da violência, se veem doravante enredados na necessidade de aumentar progressivamente os graus de violência nas tentativas de controlar os desdobramentos do que provocaram.

Outra condição importante é que as mídias aparecem como parte integrante do acontecimento por serem o que o aproxima das pessoas que estão física e simbolicamente distantes dele (DOSSE, 2013). É pela mídia que ele se faz conhecer e através da qual as pessoas podem se sentir parte dele. A mídia não cria isoladamente o acontecimento, mas auxilia na sua constituição, convoca ao engajamento e ao posicionamento do público que, assim, repercute o acontecimento e faz com que ele dure e alcance efeitos diversos.

Além das dimensões teóricas acerca das mudanças no estatuto do acontecimento na era das mídias, temos também o desafio metodológico em sua análise, verificando 
seus desdobramentos e identificando as pessoas e as instituições implicadas enquanto ele ainda está se desenvolvendo. Jornalistas e historiadores precisam mudar os registros que pressupunham investigar o acontecimento somente como o que pertencia ao passado, ainda que reverberando no presente e se projetando para o futuro. Para Pierre Nora,

No acontecimento de tipo moderno, pelo contrário, já não é o historiador que dispõe, nem mesmo o jornalista, que não é mais que o eco instantâneo duma coisa muito mais vasta, e que forma esse emaranhado da actualidade que muda completamente o nosso vivido histórico e que constitui a sua natureza. É o acontecimento que faz o historiador (NORA, 1983, p. 84).

Acontecimentos são, como afirma Nora, inflados e não precisam ter marcos temporais delimitados no passado para sua compreensão. Há o movimento de narrativa do passado com suas reverberações, mas há também uma latência de fenômenos que transbordam nas narrativas do presente. Nesse sentido, o principal problema metodológico que enfrentamos neste artigo reside em como interpretar acontecimentos que estão longe dos seus desfechos.

\section{Política e violência}

Em Hannah Arendt a política é por excelência parte essencial da ação humana, e, sobretudo, deve se assentar na convivência entre diferentes, consumando seu objetivo maior, que é a liberdade (ARENDT, 2001; 2002). Em uma potente metáfora, a autora propõe pensar a diversidade humana como uma orquestra, em que os mais variados sons e timbres são o que torna possível a beleza e a harmonia. Mais precisamente, a resposta à pergunta "o que é a política?" comporta certa diversidade de elementos, a começar pelo fato se ela ainda faria algum sentido:

Para a pergunta sobre o sentido da política existe uma resposta tão simples e tão concludente em si que se poderia achar outras respostas dispensáveis por completo. Tal resposta seria: o sentido da política é a liberdade. Sua simplicidade e concludência residem no fato de ser ela tão antiga quanto a existência da coisa política - é na verdade, não como a pergunta, que já nasce de uma dúvida e é inspirada por uma desconfiança. Essa resposta não é, hoje, natural nem imediatamente óbvia. Isso evidencia-se porque a pergunta de hoje não é simplesmente sobre o sentido da política, como antes se fazia, em essência, a partir de experiências não-políticas ou até mesmo antipolíticas. A pergunta atual surge a partir de experiências bem reais que se teve com a política, ela se inflama com a desgraça que a política causou em nosso século, e na maior desgraça que ameaça resultar delas. Por conseguinte, a pergunta é muito mais radical, muito mais agressiva, muito mais desesperada: tem a política algum sentido ainda? (ARENDT, 2002, p. 14). 
A resposta de Arendt à pergunta sobre se a política teria ainda algum sentido é positiva, mas não ingênua, pois ela reconhece as interconexões da política com a promoção de violências. Assim, negar a diversidade humana, consequentemente, coloca em risco não somente a política, mas no limite a própria humanidade, de que são exemplos, para Arendt, os regimes totalitários na Alemanha nazista e na União Soviética sob o terror stalinista, com os campos de concentração, de extermínio e de trabalhos forçados. Arendt privilegia em suas reflexões a crença na capacidade humana, a despeito de todos os horrores e violências como estratégia de domínio político, para assim superar a tentação de negar a política. Podemos vislumbrar em sua filosofia política um otimismo vigilante que tem por finalidade manter a esperança na capacidade humana de, pela ação política, alcançar o respeito pelas diferenças e pela diversidade. Nessa perspectiva, um dos desafios impostos à ação política é a superação dos diversos preconceitos que estão arraigados no senso comum, sendo o primeiro deles contra a política.

Ao se falar de política, em nosso tempo, é preciso começar pelos preconceitos que todos nós temos contra a política - quando não somos políticos profissionais. Pois os preconceitos que compartilhamos uns com os outros, naturais para nós, que podemos lançar-nos mutuamente em conversa sem termos primeiro de explicá-los em detalhes, representam em si algo político no sentido mais amplo da palavra - ou seja, algo a se constituir num componente integral da questão humana, em cuja órbita nos movemos a cada dia (ARENDT, 2002, p. 10).

O preconceito como ato político e a política da promoção do preconceito importam particularmente às nossas reflexões, posto que historicamente os regimes de exceção sempre se alimentaram dessa dupla dinâmica. É o que aflora nos acontecimentos que envolvem o ex-presidente Lula, com diversas pessoas apontando preconceitos de classe, dentre outros modos de exclusão, como componentes acionados na busca de eficácia pelos diversos agentes implicados na desconstrução de sua imagem pública (PRONER et al, 2017; 2018). A esses componentes, no entanto, a negação da política se destaca como ponto nevrálgico e não por acaso agentes da mídia, da Polícia Federal, do Ministério Público e do Poder Judiciário agem movidos politicamente, ao mesmo tempo em que afirmam ser a política o reino da degradação moral e ética.

Mas o que ameaça a política nesses termos é precisamente a violência, que Arendt distingue do poder, mesmo quando somos tentados a tomar o poder como a mais nítida manifestação da violência. Ou ainda quando confundimos a violência como forma de poder, quando ela deve ser vista como imposição de força, posto que o poder, para Arendt, deve sempre ser perspectivado a partir das comunidades políticas, portanto sua medida não é a força, mas a legitimidade outorgada pela maioria. Nesse sentido, para a autora a política é tão mais legítima quanto mais ela se identifica com a democracia.

É em Achille Mbembe $(2014 ; 2017)$ que encontramos as relações mais diretas entre 
democracia e violência. $\mathrm{O}$ autor adota perspectiva teórica que privilegia as múltiplas facetas do racismo, mostrando que se ele teve como primeiro alvo o negro da África, já de há muito se expandiu para outras raças. Ao indicar as condições de morte do considerado socialmente indigno por meio da necropolítica e tantas outras formas de violência, o pensamento de Mbembe tem diversos pontos de contato com o de Hannah Arendt, que ele cita regularmente. Em comum, ambos são otimistas vigilantes quanto às potencialidades da política como construção da possibilidade de convívio plural em um mesmo mundo.

Historicamente, segundo Mbembe, as democracias modernas, resultantes sobretudo das ideias humanistas surgidas com a Revolução Francesa, sempre estiveram atreladas, por diversos mecanismos, a variadas formas de violência. Há, portanto, uma contradição de nascedouro entre os ideais democráticos de liberdade, igualdade e fraternidade e um tipo de humanismo que, tendo a Europa como centro irradiador, considerava parte da sua missão levar adiante processos civilizatórios aos povos colonizados, humanismo que não foi capaz de promover a superação dos resultados da escravização de negros. Como consequência, segundo Mbembe,

\begin{abstract}
A ideia segundo a qual a vida em democracia é, no seu fundamento, pacífica, policiada e desprovida de violência (nomeadamente sob a forma da guerra e da devastação) não nos convence. É verdade que a emergência e a consolidação da democracia vêm a par de imensas tentativas de controlar a violência individual, de a regulamentar e reduzir, suprimindo nomeadamente as manifestações mais espetaculares e mais abjectas por reprovação moral ou por sanções jurídicas. Mas a brutalidade das democracias nunca foi senão abafada. Desde as suas origens, as democracias modernas mostraram tolerância perante uma certa violência política, inclusivamente (MBEMBE, 2017, p. 33).
\end{abstract}

Se a política não se reduz ao exercício da democracia, as referências de Hannah Arendt e de Achille Mbembe nos permitem, no entanto, pensá-la como parte essencial da vida democrática, inclusive como estratégia de aperfeiçoamento das democracias. Nunca é demais destacar, assim sendo, que em todos os períodos históricos nos quais a violência tentou suplantar a política, ou nos quais a política se fez por meio da violência, os resultados foram desastrosos, inclusive em processos como os da ascensão do nazismo e de Hitler, a princípio parte do jogo normal de regimes democráticos. Jogo democrático que supostamente marcaria os acontecimentos envolvendo o ex-presidente Lula, que passamos a examinar mais de perto, a partir de algumas narrativas jornalísticas.

\title{
Violência política envolvendo Lula: o lawfare
}

Guerra jurídica, como indica a nomenclatura em inglês, o lawfare consiste, quando aplicado sobre pessoas, em destruir reputação, interpretar a lei segundo convicções 
não sustentadas pela letra jurídica, acelerar processos - passando ao largo de provas e dificultando as estratégias de defesa -, além de outras formas de atropelo legal, sempre utilizando a mídia como importante difusora das imputações ao alvo da perseguição. Segundo Antonio E. R. Santoro e Natália L. F. Tavares,

Dois testes para aferição do Lawfare político são: (1) o autor (seja uma pessoa ou um grupo político) da ação deve usar o Direito para criar os mesmos ou similares efeitos àqueles tradicionalmente buscados pelas ações políticas e (2) a motivação do autor da ação ou de pessoas ou grupos políticos que a utilizam deve ser enfraquecer ou destruir um adversário político contra o qual o Lawfare está sendo manejado (SANTORO, TAVARES, 2017, p. 64).

Aplicados aos acontecimentos envolvendo Lula, os dois testes, segundo as análises de Proner et al $(2017 ; 2018)$ resultam positivos, com o acréscimo da participação ativa da mídia.

Definimos como recorte inicial a condução coercitiva do ex-presidente para depoimento na Polícia Federal, no aeroporto de Congonhas-SP, no dia 4 de março de 2016. Este marco faz referência à cumplicidade midiática que transformou o que deveria ser a tomada de um depoimento em um espetáculo que chegou a interromper a programação matinal da Rede Globo, para ficarmos em um exemplo paradigmático do envolvimento de diversas mídias como atrizes implicadas nos acontecimentos envolvendo Lula.

A definição da condução como coercitiva já anuncia a violência deste acontecimento. Costuma-se realizar conduções coercitivas quando o investigado resiste ou não comparece ao depoimento. No caso de Lula, não houve uma primeira intimação e o processo foi violento desde o início, não somente pela condução coercitiva, como ainda pela atuação do juiz Sérgio Moro no caso, que agrediria o princípio do "juiz natural", uma vez que o processo diz respeito a um apartamento triplex situado no estado de São Paulo e Sérgio Moro atua na justiça sediada no estado do Paraná. Como justificativa, ele alegou tratar-se de ação sob sua competência por envolver supostas corrupções ligadas à Petrobras, objeto das ações da Lava Jato, embora, na sentença em que ele condena Lula, admita não haver provas de relação entre o triplex e corrupções na Petrobras, assim como não apresenta provas de que o triplex de fato pertencesse ao ex-presidente (PRONER, et el, 2017; 2018). É fundamental destacar que Sérgio Moro defende a máxima publicidade midiática das ações da operação Lava Jato, como método para angariar apoio da opinião pública (CARVALHO, BRUCK, 2018; PRONER, et al, 2017).

Os argumentos usados por Sérgio Moro para justificar a coercitividade da condução de Lula visariam "evitar um tumulto causado pela mídia" (COLON, et al., 2016), quando mais parece que a mídia estava preparada para acompanhar e cobrir a cena. A condução coercitiva, como informa o texto publicado pela Folha de S.Paulo, gerou polêmica, com reações favoráveis e contrárias à decisão de Sérgio Moro, dentre as últimas, a do ministro do Superior Tribunal Federal, Marco Aurélio de Mello: 
Marco Aurélio de Mello, ministro do Supremo, fez críticas à opção de Moro. "Condução coercitiva? O que é isso? Eu não compreendi. Só se conduz coercitivamente, ou como se dizia antigamente, debaixo de vara, o cidadão que resiste e não comparece para depor. E o Lula não foi intimado", afirmou (COLON, et al, 2016).

Lula foi intimado, depois disso, para mais dois interrogatórios, abordando, em maio de 2017, a denúncia de que teria recebido como propina um triplex no Guarujá, litoral de São Paulo; e o segundo faz referência ao apartamento em que Lula morava, em São Bernardo do Campo, e a uma possível doação de um terreno em São Paulo pela empresa Odebrecht para o Instituto Lula. Os depoimentos foram tomados por Sérgio Moro. Em comum, a leitura das narrativas das mídias tradicionais sobre esses depoimentos indica que não há questionamento profundo sobre os métodos do juiz no julgamento, o que inclui a pertinência de que Sérgio Moro seja o responsável por essas ações contra Lula, pois se considerados os princípios do "juiz natural", o ex-presidente deveria ser julgado em São Paulo, estado onde estão as propriedades objetos dos processos, e não pela Justiça Federal sediada no estado do Paraná (PRONER, et al, 2017). Tal fato aponta para uma cumplicidade entre setores da mídia e do judiciário, em processos que afrontariam princípios elementares do Direito. Segundo Carol Proner e Ney Strozake,

A mídia hegemônica, tanto televisiva como escrita, com a pretensão de reforçar e justificar o uso de métodos excepcionais no sistema de Justiça, com o fim de convencer a opinião pública sobre a necessidade de uma "justiça justicialista" contra um "inimigo comum", ataca o cerne da democracia (PRONER, et al, 2017, pp. 15-16).

Ao longo dos acontecimentos envolvendo Lula, as ações do Ministério Público e de Sérgio Moro adotaram como métodos de investigação e formação de convicção a incorporação, como prova, de notícias publicadas no jornal O Globo, como Lula afirma em depoimento: "Na minha condenação, o senhor cita o jornal O Globo 15 vezes, e não cita... cita acho que cinco testemunhas minhas que vieram aqui. Então precisa ler outros jornais..." (UOL, 2017). Por isso, Lula se refere aos procuradores, mas também ao poder judiciário articulado em sua condenação, como "reféns da imprensa", destacando a mídia como parte integrante dos acontecimentos que o envolvem (SIMÕES, 2016).

Apesar da inexistência de provas irrefutáveis (PRONER, et al, 2017; 2018), Lula foi condenado pelo juiz Sérgio Moro, em primeira instância, a uma pena de 9 anos e seis meses. Após apelação ao Tribunal Regional Federal-4, a pena foi aumentada, por unanimidade, para 12 anos e 1 mês, abrindo caminho para a prisão do ex-presidente, em processo considerado célere. 
Levantamento feito pela Folha aponta que, em 2017, apenas dois processos públicos por corrupção foram decididos em menos de 150 dias pelo TRF-4. No caso de lavagem de dinheiro, nenhum de mérito foi julgado - foi apenas decidido em um caso que a competência para a decisão é da Justiça Federal do Rio Grande do Sul (MARQUES, et al., 2017).

No dia 6 de abril de 2018, o juiz Sérgio Moro, acompanhado dos olhares atentos da mídia que se preparava para anunciar que finalmente tinham conseguido prender o líder político, decretou que Lula se entregasse à Polícia Federal até as $17 \mathrm{~h}$ daquele mesmo dia.

Com plantões na televisão, coberturas ao vivo pelas redes sociais e sites da Internet, a violência simbólica contida na violência jurídica dessa condenação (PRONER, et al, 2017; 2018) foi acompanhada pelo Brasil e pelo mundo. Havia expectativa sobre a hora em que Lula se entregaria, e se o faria. Uma multidão de pessoas se reuniu em frente ao Sindicato dos Metalúrgicos do ABC Paulista para prestar apoio ao ex-presidente, que estava no prédio reunido com assessores e outros membros do Partido dos Trabalhadores e de partidos aliados.

Dada a hora estipulada por Moro, Lula não se entregou. Faria no dia seguinte um ato ecumênico em memória de sua esposa, Marisa Letícia. Lula discursou na manhã seguinte para as pessoas que estavam no entorno do sindicato, onde ele passara a noite. Foi acompanhado no palanque pelos apoiadores que, assim como ele, acreditavam tratar-se de uma condenação política e de cunho eleitoral. Depois da missa, decidiu que se entregaria.

O ex-presidente se entregou à Polícia Federal, em São Paulo, no dia 7 de abril de 2018 e foi levado a Curitiba na mesma noite, onde está preso. A violência dos acontecimentos a ele relacionados não pararam. Líderes religiosos que tentaram visitá-lo nos primeiros dias de cárcere, como Juan Grabois, assessor do Papa Francisco para assuntos de justiça e paz, e Leonardo Boff, foram impedidos de entrar. Assim como governadores e a presidenta Dilma Rousseff. Adolfo Esquivel, prêmio Nobel da paz em 1980, que acompanhava Boff, também não pôde visitar Lula (BOFF, 2018).

Outro alvoroço midiático, com uma disputa de sentidos travada entre mídia tradicional e aquelas que se apresentam como alternativas, ocorreu no dia 8 de julho, data em que o desembargador Rogério Favreto, naquele domingo responsável pelo plantão do TRF-4, emitiu decisão para soltar Lula até às 17h12 daquele dia. Mas Sérgio Moro, de férias em Portugal, impediu que a Polícia Federal cumprisse a ordem do desembargador de plantão, até que outros desembargadores do TRF-4 anulassem o habeas corpus. Outra vez, procedimentos relativos aos acontecimentos envolvendo Lula suscitaram polêmicas jurídicas e políticas, particularmente porque a decisão de um desembargador de plantão não poderia ser contestada por colega que não estava em serviço naquele dia, além disso em férias, o que o tornou não mais parte interessada nos procedimentos jurídicos, não podendo emitir qualquer ordem naquela disputa política protagonizada pelo judiciário.

O desfecho que se delineava desde o início dos acontecimentos envolvendo Lula 
era o impedimento da sua candidatura às eleições presidenciais de 2018, tomada pelo Tribunal Superior Eleitoral. A decisão do TSE contrariou o Comitê de Direitos Humanos da ONU, que recomendava a aceitação da candidatura de Lula, por entender que ainda não estão esgotados todos os recursos jurídicos a que ele tem direito, o que preservava sua possibilidade de candidatar-se.

A desobediência à decisão da ONU e suas possíveis repercussões para o Brasil foram discutidas com mais ênfase nos sites de proposta alternativa. A notícia na mídia tradicional se mostrou corriqueira, como se um candidato qualquer, e não aquele que estava em primeiro lugar nas pesquisas de intenção de voto até aquela data (31 de agosto), tivesse impedida sua candidatura.

Desde que está encarcerado em Curitiba, decisões judiciais reiteradamente impediram que Lula concedesse entrevistas até a semana de 25 de abril de 2019, seja justificando questões de segurança, seja alegando que em período eleitoral entrevistas dele poderiam interferir nos resultados da disputa. Assim como no episódio do habeas corpus de soltura do ex-presidente, as polêmicas relativas às proibições de entrevistas alcançaram o ápice com decisões e contra-decisões, no STF, no que foi retratado pelo repórter César Fonseca (2018), no Brasil 247, como a confirmação de que Lula era um preso político.

\section{Considerações finais}

A prisão e impedimento da candidatura de Lula à presidência contribuiu decisivamente para a eleição de Jair Bolsonaro, político explicitamente associado a atitudes autoritárias e de desrespeito à diversidade humana, na contramão dos pensamentos de Hannah Arendt e de Achille Mbembe sobre a política como possibilidade da não violência, a despeito de todos os desafios.

As violências políticas contra Lula, praticadas por decisões jurídicas que não deveriam ser contaminadas por motivação política, seguem seu curso, em turbilhão que acrescenta novas dimensões de violência como necessidade de tentar manter o curso dos acontecimentos. No que diz respeito às denúncias de motivações políticas nas ações de todos os agentes envolvidos com a Operação Lava Jato, e particularmente do juiz Sérgio Moro, este, ao aceitar o convite para ser ministro da Justiça do governo de Jair Bolsonaro, torna explícita a natureza política das decisões tomadas em relação ao ex-presidente Lula, confirmando os pressupostos do lawfare aqui discutidos. Notícia do Brasil 247 dá conta de que Bolsonaro reconheceu a importância de Sérgio Moro:

\footnotetext{
"Você tem que reconhecer o trabalho dele, muito bem feito. Inclusive em função do combate à corrupção, da operação Lava Jato, as questões do mensalão, entre outros, me ajudou a crescer, politicamente falando", disse Bolsonaro em sua primeira coletiva a jornalistas como presidente eleito (BRASIL 247, 2018).
} 
Como buscamos evidenciar, se diversos acontecimentos políticos contêm em si a potencialidade da violência, tentar conter os seus transbordamentos pode resultar em ações cujo crescendo de violência é inevitável. Ações que têm na mídia componente fundamental como parte das estratégias e práticas de lawfare. Limitamos nossa afirmação aos acontecimentos políticos analisados neste artigo, de modo a evitar possíveis universalismos, inclusive preservando a possibilidade da ação política como a promoção da diversidade, segundo propõe Hannah Arendt. Nessa perspectiva, acontecimentos políticos tenderiam precisamente ao combate à violência.

No que se refere ao desafio de analisar acontecimentos em curso, haverá sempre a impossibilidade de se chegar a conclusões definitivas, restando como gesto de pesquisa delimitar temporalmente alguns eventos, como procedemos em relação às violências políticas envolvendo Lula. Se tal procedimento não resolve as dificuldades de análise de acontecimentos do e no presente, ele ao menos permite enfrentar o necessário escrutínio do que nos ameaça de imediato, sem postergar, a quem pesquisará em um futuro distante, aquilo que nos diz respeito como investigadores no presente.

No que se refere à política e à democracia a pergunta angustiante é: têm elas salvação ou sentido, para retomar a questão central de Hannah Arendt (2002)? Continuam elas apostas possíveis para o futuro, quando nos deparamos com acontecimentos como os que analisamos?

Democracia e política constituem projetos em permanente construção, não realidades dadas de vez para sempre. Como parte das contradições de ambas, acontecimentos violentos e a política como violência devem ser objeto permanente de escrutínio e combate.

Carlos Alberto Carvalho é professor associado do Departamento de Comunicação Social da Universidade Federal de Minas Gerais e bolsista produtividade do CNPq. carloscarvalho0209@gmail.com

Maria Gislene Carvalho Fonseca é doutora em Comunicação Social pela Universidade Federal de Minas Gerais.

mgisacarvalho@gmail.com

\section{Referências}

ARENDT, H. Sobre a violência. Rio de Janeiro: Relume-Dumará, 2001.

O que é a política? Rio de Janeiro: Bertrand Brasil, 2002.

BOFF, L. Como e por que eu e Perez Esquivel fomos impedidos de visitar Lula. DCM. 22 abr. 2018. Disponível em: Disponível em https://www.diariodocentrodomundo.com.br/como-e-por-que-eu-eperez-esquivel-fomos-impedidos-de-visitar-lula-por-leonardo-boff/. 
BRASIL 247. Bolsonaro reconhece que Moro foi seu cabo eleitoral. Brasil 247. 01 nov. 2018. Disponível em: https://www.brasil247.com/pt/247/poder/373930/Bolsonaro-reconhece-que-Morofoi-seu-cabo-eleitoral.htm.

CARVALHO, C. A.; BRUCK, M. S. Vazamentos como acontecimento jornalístico: notas sobre performatividade mediática de atores sociais. Revista Famecos, Porto Alegre, v. 25, n. 3, p. 1-20. DOI: http://dx.doi.org/10.15448/1980-3729.2018.3.29713.

COLON, L., et al. Condução coercitiva de Lula foi decidida para evitar tumulto, diz Moro. Folha de S.Paulo. 04 mar. 2016. Disponível em http://www1.folha.uol.com.br/poder/2016/03/1746437conducao-coercitiva-de-lula-foi-decidida-para-evitar-tumulto-diz-moro.shtml.

DOSSE, F. Renascimento do acontecimento: um desafio para o historiador: entre Esfinge e Fênix. São Paulo: Editora Unesp, 2013.

FONSECA, C. Toffoli confirma Lula preso político. Brasil 247. 02 out. 2018. Disponível em: https:// www.brasil247.com/pt/colunistas/cesarfonseca/370831/Toffoli-confirma-Lula-preso-político.htm

GIELOW, I. Lula chega a 39\%, aponta Datafolha; sem ele, Bolsonaro lidera. Folha de S.Paulo. 22 ago. 2018. Disponível em: https://www1.folha.uol.com.br/poder/2018/08/lula-chega-a-39-apontadatafolha-sem-ele-bolsonaro-lidera.shtml.

MARQUES, J., et al. Tribunal julga caso de Lula com a rapidez de casos mais simples. Folha de S.Paulo. 31 dez. 2017. Disponível em: https://www1.folha.uol.com.br/poder/2017/12/1947097tribunal-julga-caso-de-lula-com-a-rapidez-de-acoes-mais-simples.shtml.

MBEMBE, A. Crítica da razão negra. Lisboa: Antígona, 2014

Políticas da inimizade. Lisboa: Antígona, 2017.

NORA, P. Entre memória e história: a problemática dos lugares. Projeto História, (10), 1993, pp. 7-28. Disponível em: https://revistas.pucsp.br/index.php/revph/article/viewFile/12101/8763.

O acontecimento e o historiador do presente. In: NORA, Pierre e outros. A nova história. Lisboa: Edições 70, 1984, p. 45-56.

PRONER, C. et al. (orgs.). Comentários a uma sentença anunciada: o processo Lula. Bauru: Canal 6, 2017.

Comentários a um acórdão anunciado: o processo Lula no TRF4. São Paulo: Outras Expressões, 2018.

QUÉRÉ, L. Entre fait et sens, la dualité de l'événement. Réseaux n. 5, p. 183-218, 2006.

A dupla vida do acontecimento: por uma realidade pragmatista. In: Acontecimento: reverberações. FRANÇA, V. R. V. \& OLIVEIRA, L. (orgs.). Belo Horizonte: Autêntica Editora, 2012.

SANTORO, E. R. e TAVARES, N. L. F. O uso do sistema penal como lawfare político. In: BASSO, A. B. et al. (coord.). Criminologias e política criminal. Florianópolis: Conpedi, 2017.

SIMÕES, E. Lula diz que procuradores que o acusam são "reféns da imprensa". Exame. 21 out. 2016. Disponível em https://exame.abril.com.br/brasil//ula-diz-que-procuradores-que-o-acusamsao-refens-da-imprensa/.

UOL. Leia a íntegra do interrogatório de Lula a Moro. UOL. 19 set. 2017. Disponível em: https://noticias. uol.com.br/politica/ultimas-noticias/2017/09/13/leia-a-integra-do-depoimento-de-lula-a-moro.htm. 